\title{
A review on the potential role and application of GIS in the management of substance abuse
}

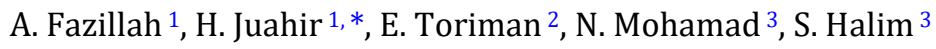 \\ ${ }^{1}$ East Coast Environmental Research Institute, Universiti Sultan Zainal Abidin, Gong Badak Campus, 21300 Terengganu, Malaysia \\ ${ }^{2}$ Faculty of medicine, Universiti Sultan Zainal Abidin, Gong Badak Campus, 21300 Terengganu, Malaysia \\ 3Medical Centre, Universiti Sultan Zainal Abidin, Gong Badak Campus, 21300 Terengganu, Malaysia
}

\section{A RT I C LE IN F O}

\section{Article history:}

Received 26 January 2017

Received in revised form

9 March 2017

Accepted 15 March 2017

Keywords:

Geographic information system

Substance abuse

GIS analysis spatial distribution

Modelling

\begin{abstract}
A B S T R A C T
Health Geography can provide a spatial comprehension of a population's health, the environment's effect on health and disease and the distribution of disease in an area. It also deals with accessibility to health care and spatial distribution of health care providers and diseases. In this paper, we elaborate the importance of GIS in the public health fields and the restraint that faced in the implementing of GIS. In addition, we also highlighted the potential of GIS in substance abuse management based on the reviewing other studies, including understanding the geographic distribution of substance abuse problems, risk area spatial accessibility to the treatment center, and network analysis and modelling. Despite the ability of GIS in handling these cases, certain limitations were identified to be obstacles of the application of this technology for substance abuse. For example, the GIS application requires high expertise and technical users to handle the system. Through the power of GIS analyses, it is capable in identifying the risk area, monitoring the substance abuse problems, planning the strategic program, and providing a systematic system to aide in decision-making processes.
\end{abstract}

(C) 2017 The Authors. Published by IASE. This is an open access article under the CC BY-NC-ND license (http://creativecommons.org/licenses/by-nc-nd/4.0/).

\section{Introduction}

The term GIS is widely applied in geographically oriented computer technology. Many definitions have been given to GIS, but generally GIS can be defined as a computer based integrated database management system that stores a large amount of data in the form of attribute and spatial data which are captured, stored, retrieved, processed and analysed with the unique visualization and geographic analysis by maps (Reddy et al., 2013). The GIS technology allows geographic patterns, which would not be apparent using conventional statistical methods, to emerge from data and be displayed in easily understood format by nontechnical users in a map (Petronis et al., 1995). GIS consists of at least five main components which are hardware, software, data, methods and people. Hormon and Anderson (2003) stated that hardware runs the GIS, software is the core of GIS, while data is the information needed to support these

\footnotetext{
* Corresponding Author.

Email Address: hafizanj@gmail.com (H. Juahir)

https://doi.org/10.21833/ijaas.2017.05.013

2313-626X/C) 2017 The Authors. Published by IASE.

This is an open access article under the CC BY-NC-ND license

(http://creativecommons.org/licenses/by-nc-nd/4.0/)
}

components, and methods are the applications and programs used to work and lastly, people are the users of the system.

The advanced and technologically elegant tool of GIS makes it a tool used in various fields. Nowadays, both public and private sectors are developing innovative ways to harness the data integration and spatial visualization power of GIS. The GIS database provides a comprehensive framework and organization of spatial and non-spatial data and has become a focused tool to help planning and decision making. The function of GIS not only focuses on the map, but it also can integrate all the data, provides users with advanced modelling functions, tools for design and planning, hence has become a tool to help in decision making (Mennecke, 1997).

GIS is a powerful tool because it is used to support data analysis and can help decision makers to address all the information needed. The strength of GIS in contributing to decision making lies in the ability of the system to store and manipulate data based on its spatial location (Keenan, 2003; Mishra, 2009). The health care industry has recently begun to realize the tremendous potentials of GIS. Over maps and geographic features, it is useful to show decision related information and relationship between objects (Rayed, 2012). Researchers believe 
that there is a strong connection between environmental health and disease, prompting them to explore how it is linked together (Thomas et al., 2008). McLafferty (2003) proposed that the contribution of geographers and substance abuse field can be achieved through the studying of the connection between the environment and health via their geographic tools like GIS.

For the use of public health, GIS is a very useful mechanical tool, which may be used to map where people are diagnosed with particular diseases, besides improving the understanding of data through visualization and analysis, then used for planning, monitoring and surveillance (Elebead et al., 2012; Fisher and Myers, 2011). Recently, a GIS based approach received great attention in the field of substance abuse (Latkin et al., 1998). A large geospatial database can be developed by integrating the geographic information to other data of substance abuse. The database then can be linked to the GIS through physical features such as addresses and location coordinates (Mason et al., 2004). Therefore, this paper aims to review the application of GIS in the substance abuse (drug abuse) field which is helpful in the means of research.

\section{GIS approach towards substance abuse}

GIS is still infrequently used in substance abuse studies. Nevertheless, the method has attained an outstanding place among professionals in this study area due to the innovative information offered in understanding, analyzing monitoring and presenting research. The awareness of researchers in the determinants of substance abuse problems has an association between geography and other social factors prompting them to explore the ability of GIS in substance abuse research. GIS is not only helping in the identifying of sources of substance abuse problems, but it also contributes to the eradication of the problem of substance abuse itself. There are many analyses in GIS which can be used to integrate and analyze a huge amount data from disparate sources (Geanuracos et al., 2007) and analyze data (spatial and non-spatial data) as long as the data is linked to a geodatabase (Berke, 2010). In this paper, we will examine previous studies on the application of GIS in substance abuse and highlight the role of GIS in this particular area.

Universally, GIS does not only serve for making disease maps; instead, it is capable in leading to a better understanding of the relationship between a disease and its environmental surrounding (Yomralioglu et al., 2009). The advanced technology of GIS is proven through the understanding of geographic distribution of a disease. In the study of substance abuse, Zhou et al. (2014) employed a geographic autocorrelation analysis and geographic scan statistics to characterize the geographic pattern of HIV and HCV infections among drug users at the township level. Brownstein et al. (2010) applied GIS to study the distribution of substance abuse and identify its hot spot areas, plus investigate the similarities of the location which fall in the same cluster. Green and Pope (2008) also used GIS to compare the profiles of substance abuse treatment attendees in New Orleans to Houston based on the distribution of care centre for substance abuse client. A study by Toriman et al. (2015) developed a map to display the distribution of drug addiction in Terengganu to identify hot spot areas of drug addiction and Buxton et al. (2008) also produced a map of needle distribution sites showing the limitation of primary distribution and assisted health authorities to assess the reaching of supplies in their locations. Through GIS, a disease mapping would make it easy to update information and identify hot spot areas (Kenu et al., 2014; Srivastava et al., 2009). Sanders et al. (2013) used Getis-Ord Gi* to identify the hot spot areas for their study.

Through analyzing layers of substance abuse problems, risk areas could be determined. Mendoza et al. (2013) analyzed spatial consideration as a component of the risk assessment in Buffalo, New York. The influence of environmental factors to drug abuse, addiction and seeking treatment attracted researchers to study this field using the GIS approach (Mclafferty, 2008). Recent advanced application of GIS in analyzing environmental factors related to health with regard to identifying the distribution of the diseases and the hot spot areas were very helpful in finding the proper solution to the problems (Botto et al., 2005; Seid et al., 2014; Shirayama et al., 2009).

Many studies on substance abuse attempted to identify the risk areas of substance abuse such as a research conducted by Mendoza et al. (2013) which used GIS to determine risk areas. The results showed that there were risk and neighbourhood factors associated with substance abuse treatment. The risk factors can be determined using GIS through ecological parameters analyses (Daash et al., 2009). In a study conducted by Curtis et al. (2013), they created a map highlighting the risk areas which required public health training through detecting high diabetes prevalence but low resources. There are a few studies which used GIS to create a map with the distribution of dengue to identify the high risk areas, thus implementing prevention strategies and monitoring the spreading of the disease. A little twist was carried out by Wen et al. (2010) which identified high risk areas of dengue by taking into account three temporal indices.

Other than that, a map of substance abuse developed contain meaningful information such as identified hot spot and cold spot areas of substance abuse problems, analyzing the spatial analysis and investigating the environmental surroundings which affect the problem. A previous study by Colasante et al. (2008) claimed that events which occur in a specific area are influenced by their surroundings. This can be investigated through the autocorrelation analysis of GIS. In a study conducted by Hunt et al. (2008), a polygon feature was used to define the areas which should be investigated for their study, as the idea of market activity of dug market may be 
influenced by the adjacent area. GIS also does not leave behind analyses of neighbourhood factors in substance abuse issues (Brown, 2013). Neighbourhood factors which impact drug health were explored through GIS analysis in a study by Cooper et al. (2009). In a study conducted by Williams and Latkin (2007), they found a poor neighbourhood was significantly associated with the abuse of heroin and cocaine. According to Sorensen (1997), many law enforcement departments conducting crime analysis use maps, including detecting crimes caused by substance abusers. Chikumba (2009) used GIS to produce a map helping drug officers in attaining information about environmental factors, location of existing facilities and acting as an information tool through the integrating of spatial data and drug logistic data. Brouwer et al. (2006) agreed that environmental surroundings and geographic boundaries affect the scene of substance abuse, where in their study they used GIS to analyse the effect of environmental factors such as migration, neighbourhood characteristics and proximity which contribute to substance abuse.

Increasingly, more studies on substance abuse using GIS to measure the spatial accessibility to treatment centres have been conducted. For example, Kao et al. (2014) explored the spatial accessibility of drug treatment outpatients. In a study by Pang and Lee (2008) to identify the coverage of methadone maintenance clinic to heroin users, GIS was used for the measurement of districtbased geographic coverage in which methadone clinic should be located at the location needed by heroin users. This was supported by Wong et al. (2010), who used GIS to study the assessing of spatial distribution of methadone clinic clients and their access to treatment. They concluded that convenient locations of methadone clinics were needed for effectiveness of the treatment process. The spatial accessibility has close relation to distance analysis.

As an effort for rehabilitation process of substance abuse, the distance between their treatment centres play a large role in the effectiveness of the treatment, where the closer the treatment centre is to the home of the substance abuser, the better the outcome of the treatment is. In fact, Guagliardo (2004) used a kernel density estimation method to analyse the accessibility to the treatment services.

Network analyses offered by the GIS tool are also used to analyze the closest route of the study subject (Reddy et al., 2013). In the substance abuse field, network analysis is performed to identify the closest treatment centre and the shortest route. The application of GIS to determine the impact of distance through non spatial data to access the healthcare is rapidly growing (Higgs, 2009). There are certain researches which applied GIS to analyse the distance of the treatment centre. In a study by Guerrero et al. (2011), the GIS approach was used to map the distribution of Latino residents and calculate the distance between census block and facility offering services. In a study by Guerrero et al. (2013), they used GIS to determine the travel distance from the outpatients of substance abuse and treatment facilities with services. In addition to their study, they analysed the data to identify hot spot areas and clusters of census tracts with high density population to the treatment services using network analysis and autocorrelation analysis.

A previous study by Mason et al. (2004) utilised the GIS to examine the travel distance between the homes of substance abusers (urban teenagers) to the risk area with the consideration of social network and geography features. Doi et al. (2015) proposed a probabilistic model based on GIS to analyse patient accessibility to hospitals considering the distance and travel time. They found out that their proposed method resulted more accurate analyses. Using the advantages of buffering and overlay method in GIS, more accurate spatial variation can be revealed in shortage designation practice (Luo, 2004). O'Neil (2003) used transportation specialised GIS to analyse the distance between the pair of residential zip codes with the nearest emergency hospital department.

Unfortunately, linear distance is not valid in measuring travel distance because other factors may influence the travel distance like the terrain, the situation of the road and transportation issues. Other evidence showed that travel distance may impact the travel time and there is strong association between straight line distances with travel time (Luo, 2004). It should be considered that geographical features and topography may influence time travel of substance abusers to the treatment centre. Bruneau et al. (2008) studied the impact of physical distance from needle exchange on HIV behaviours. According to Masoodi and Rahimzadeh (2015), Response time method is the best technique to provide a better assessment of accessibility to healthcare services. In a study by Rosero-Bixby (2004), GIS was used to measure the accessibility to healthcare centres which considered all supply and demand data in Costa Rica; this resulted to the integration of these data in GIS platform to be powerful in achieving the goal.

As an effort of eradicating substance abuse problems, GIS can be modelled to help police and stake holders involved in identifying hot spot and risk areas, thus assist in planning the solution for the problems. In a study by Hunt et al. (2008), they developed a deterrence model based on GIS compromising the information of dealer locations, distribution of dealers in the market and the relationship between dealers and location and crimes, thus identifying the target of enforcement and planning suitable strategies. This model suggested reducing the violence related to over street dealing. Through developing GIS content, all the information related assists decision makers to establish proper planning in overcoming a problem as studied by Geanuracos et al. (2007) where they developed a database of demography, health and 
crime data to access the transition of HIV disease. In addition, a study by Davidson et al. (2011) used the GIS approach by developing a database and generating a map containing collected data to improve needle exchange service delivery. Zhu et al. (2006) found that there is a significant link between hot spot areas of substance abuse with criminal problems.

Besides that, the ability of GIS in delivering information cannot be denied. Elmahdi and Afify (2007) developed a user interface of GIS to enhance the presentation of their study; as a result, even nontechnical users are able to easily browse and make comparisons among the results needed. The advantage of GIS in spatial data preparation and visualizing can become a tool for developing spatial decision support systems in varies fields (Choi et al., 2005). In the advancement of developing web based applications on GIS, it is currently very important to store health data in the central server where it can be used anytime and anywhere using internet connection. The development of Web based GIS is currently growing in health studies to deliver, share and organize data (Boulos and Honda, 2006; Lazakidou, 2010). The capabilities of GIS in publishing and sharing information via internet can be an effective way of working in many applications (Boulos and Honda, 2006). A number of papers have been presented by Boulus on his study to create an interactive map to help authorities in problems detecting and solving many health issues (Boulos, 2004) through open sourced web GIS software (Boulos, 2005; Boulos and Honda, 2006). We summarise the application of GIS in substance abuse study as shown in Table 1.

Table 1: Substance abuse research using GIS analysis

\begin{tabular}{|c|c|c|c|}
\hline Number & Title & Author & GIS tool \\
\hline \multicolumn{4}{|c|}{$\begin{array}{l}\text { Environmental Factors } \\
\end{array}$} \\
\hline 1 & $\begin{array}{c}\text { The geographic distribution patterns of HIV-, HCV- and co-infections } \\
\text { among drug users in a national methadone maintenance treatment } \\
\text { program in Southwest China }\end{array}$ & $\begin{array}{l}\text { Zhou et al. } \\
\text { (2014) }\end{array}$ & $\begin{array}{l}\text { Autocorrelation analysis, } \\
\text { geographic scan statistic }\end{array}$ \\
\hline 2 & $\begin{array}{c}\text { Geographic Informations Systems and Pharmacoepidemiology: Using } \\
\text { spatial cluster detection to monitor local patterns of prescription opioid } \\
\text { abuse. }\end{array}$ & $\begin{array}{l}\text { Brownstein et } \\
\text { al. (2010) }\end{array}$ & GIS unspecified \\
\hline 3 & $\begin{array}{c}\text { Using a GIS Framework to Assess Hurricane Recovery Needs of Substance } \\
\text { Abuse Center Clients in Katrina- and Rita-Affected Areas, Geography and } \\
\text { Drug Addiction. }\end{array}$ & $\begin{array}{l}\text { Green and Pope } \\
\qquad(2008)\end{array}$ & $\begin{array}{l}\text { Geocoding, buffer analysis, } \\
\text { autocorrelation analysis }\end{array}$ \\
\hline 4 & $\begin{array}{c}\text { Spatial and Temporal Assessment on Drug Addiction Using Multivariate } \\
\text { Analysis and GIS }\end{array}$ & $\begin{array}{l}\text { Toriman et al. } \\
\quad(2015)\end{array}$ & GIS unspecified \\
\hline 5 & $\begin{array}{l}\text { Harm Reduction Strategies and Services Communities. More than just } \\
\text { needles: An evidence-informed approach to enhancing harm reduction } \\
\text { supply distribution in British Columbia. }\end{array}$ & $\begin{array}{l}\text { Buxton et al. } \\
\qquad(2008)\end{array}$ & GIS unspecified \\
\hline 6 & $\begin{array}{c}\text { Italian of Public Health Spatial Analysis of Drug-Related Hospital } \\
\text { Admissions : An Auto-Gaussian Model to Estimate the Hospitalization } \\
\text { Rates in Italy. }\end{array}$ & $\begin{array}{l}\text { Colasenta et al. } \\
\qquad(2008)\end{array}$ & GIS unspecified \\
\hline 7 & $\begin{array}{c}\text { Using GIS to identify drug markets and reduce drug-related violence a } \\
\text { data-driven strategy to implement a focused deterrence model and } \\
\text { understand the elements of drug markets. }\end{array}$ & $\begin{array}{l}\text { Hunt et al. } \\
\text { (2008) }\end{array}$ & Spatial analysis \\
\hline 8 & $\begin{array}{l}\text { Geographic approaches to quantifying the risk environment: A focus on } \\
\text { syringe exchange program site access and drug-related law enforcement } \\
\text { activities. }\end{array}$ & $\begin{array}{l}\text { Cooper et al. } \\
\text { (2009) }\end{array}$ & ArcInfo \\
\hline 9 & $\begin{array}{l}\text { Neighborhood Socioeconomic Status, Personal Network Attributes, and } \\
\text { Use of Heroin and Cocaine }\end{array}$ & $\begin{array}{l}\text { Williams and } \\
\text { Latkin (2007) }\end{array}$ & ArcView \\
\hline 10 & $\begin{array}{c}\text { Application of geographic information system (GIS) in drug logistics } \\
\text { management information system (LMIS) at district level in Malawi: } \\
\text { Opportunities and challenges. AFRICOMM 2009, }\end{array}$ & $\begin{array}{l}\text { Chikumba } \\
\text { (2009) }\end{array}$ & GIS unspecified \\
\hline 11 & $\begin{array}{c}\text { Integrating GIS into the Study of Contextual Factors Affecting Injection } \\
\text { Drug Use Along the Mexico / US Border. }\end{array}$ & $\begin{array}{l}\text { Brouwer et al. } \\
\quad(2006)\end{array}$ & ArcGIS \\
\hline 12 & $\begin{array}{l}\text { Using GIS To Describe Risk And Neighbourhood-Level Factors Associated } \\
\text { With Substance Abuse Treatment Outcomes. }\end{array}$ & $\begin{array}{l}\text { Mendoza et al. } \\
\text { (2013) }\end{array}$ & Geocoding \\
\hline 1 & $\begin{array}{l}\text { Spatial Accessibility To Treatment Centres } \\
\text { Spatial accessibility of drug treatment facilities and the effects on locus of } \\
\text { control, drug use, and service use among heroin-injecting Mexican } \\
\text { American men }\end{array}$ & Kao et al. (2014) & ArcGIS \\
\hline 2 & $\begin{array}{l}\text { Measuring the geographic coverage of methadone maintenance } \\
\text { programme in Hong Kong by using geographic information system (GIS). }\end{array}$ & $\begin{array}{l}\text { Pang and Lee } \\
\quad(2008)\end{array}$ & ArcGIS \\
\hline 3 & $\begin{array}{l}\text { Assessing the spatial distribution of methadone clinic clients and their } \\
\text { access to treatment }\end{array}$ & $\begin{array}{l}\text { Wong et al. } \\
\text { (2010) }\end{array}$ & Spatial statistical analysis \\
\hline 4 & $\begin{array}{l}\text { Availability of substance abuse treatment services in Spanish: a GIS } \\
\text { analysis of Latino communities in Los Angeles County, California }\end{array}$ & $\begin{array}{l}\text { Guerrero et al. } \\
\qquad \text { (2011) }\end{array}$ & Geocode, spatial analysis \\
\hline 5 & $\begin{array}{l}\text { Travel distance to outpatient substance use disorder treatment facilities } \\
\text { for Spanish-speaking clients }\end{array}$ & $\begin{array}{l}\text { Guerrero et al. } \\
\qquad(2013)\end{array}$ & $\begin{array}{l}\text { ArcGIS, ESRI Network } \\
\text { analyst extension and } \\
\text { OpenGeoDa }\end{array}$ \\
\hline 6 & Substance use, social networks, and the geography of urban adolescents. & $\begin{array}{l}\text { Mason et al. } \\
\quad(2004)\end{array}$ & Geocoding \\
\hline 7 & $\begin{array}{l}\text { Associations between HIV-related injection behaviour and distance to and } \\
\text { patterns of utilisation of syringe-supply programmes }\end{array}$ & $\begin{array}{l}\text { Bruneau et al. } \\
\quad(2008)\end{array}$ & Unspecified \\
\hline
\end{tabular}




\section{The challenges of the GIS application in substance abuse}

Although GIS provides a powerful system and suites to help decision makers explore and understand certain classes of problems, there are a number of challenges which should be addressed. Among the impediments in applying GIS in most public health researchers are limited availability of data, high cost, the ability to learn GIS software and perceptions stating that GIS is only suitable for quantitative data rather than qualitative data (Brown, 2013). In order to run and maintain GIS, it is rather costly since both hardware and software are needed to be purchased. In addition, all data used have to be checked for accuracy, completeness, reliability, validity and quality. It should be noted that all data collected must have their coordinates to link with the feature in the map. The GIS application requires high expertise and technical users to handle the system. Therefore, organizations have to train their staff in the specific use of the system and fundamental concepts of geography and cartography (Mullner et al., 2004). The accuracy of maps produced depends on the knowledge and skills of the analyst who uses this system. Thus, the GIS method can deliver information systematically as desired by the consumer (Rafalski and Mulner, 2003). However, it is crucial to note that GIS cannot make a decision, but it can only assist in improving the decision making process.

\section{Conclusion}

The application of GIS in research has been growing due to the ability of GIS itself in analyzing. The GIS application, as a tool in health care research is widely used, but there are limited studies which used GIS in investigating substance abuse. Clearly, there is an opportunity in the healthcare industry to strengthen their understanding towards substance abuse research; not only to produce a map, but to use GIS as decision support tool. Through the application of GIS in substance abuse management, the relationship between substance abuse and environmental factors can be identified and support data, thus help decision makers to eradicate issues in the field. In conclusion, this study has highlighted the advantages of GIS as a sophisticated tool for managing substance abuse problems which are to understand geographic distribution of substance abuse, identifying risk areas, analysing spatial accessibility of substance abusers to treatment centres, analysing network analyses to help abusers in getting more treatment, and modelling methods to help stakeholders involved. Therefore, the power of GIS technology should be harnessed and the application of GIS should be extended in substance abuse studies. The advancement in computer technology and GIS application, in particular, suggests that the GIS application will be an important system in management of substance abuse in the future.

\section{Acknowledgment}

The authors would like to thank Niche Research Grant Scheme

(NRGS-KPM)

UniSZA/NRGS/2013/RR057 for their funding of this research. A special thank goes to the Ministry of Higher Education Malaysia, Prison Department of Malaysia (Marang) and UniSZA for providing general assistants to this project. Finally yet importantly, greatly thankful to East Coast Environmental Research Institute (ESERI) upon kind assistance in data analysis techniques and peer support in completing this paper.

\section{References}

Berke EM (2010). Geographic information systems (GIS): Recognizing the importance of place in primary care research and practice. The Journal of the American Board of Family Medicine, 23(1): 9-12.

Botto C, Escalona E, Vivas-Martinez S, Behm V, Delgado L, and Coronel P (2005). Geographical patterns of onchocerciasis in southern Venezuela: relationships between environment and infection prevalence. Parassitologia, 47(1): 145-150.

Boulos MNK (2004). Towards evidence-based, GIS-driven national spatial health information infrastructure and surveillance services in the United Kingdom. International Journal of Health Geographics, 3:1. https://doi.org/10.1186/1476072X-3-1

Boulos MNK (2005). Web GIS in practice III: Creating a simple interactive map of England's Strategic Health Authorities using Google Maps API, Google Earth KML, and MSN Virtual Earth Map Control. International Journal of Health Geographics, 4: 22. https://doi.org/10.1186/1476-072X-4-22

Boulos MNK and Honda K (2006). Web GIS in practice IV: Publishing your health maps and connecting to remote WMS sources using the open source UMN map server and DM solutions map lab. International Journal of Health Geographics, 5: 6. https:/doi.org/10.1186/1476-072X-5-6

Brouwer KC, Weeks JR, Lozada R and Strathdee A (2006). Integrating GIS into the study of contextual factors affecting injection drug use along the Mexico / US Border. In: Thomas YF, Richardson D, and Cheung I (Eds.), Geography and Drug Addiction: 27-42. Springer, Amsterdam, Netherlands.

Brown JS (2013). Emerging applications of geographic information systems (GIS) in community and local mental health research. Journal of Local and Global Health Perspective, 2013: 5. https://doi.org/10.5339/jlghp.2013.5

Brownstein JS, Green TC, Cassidy TA and Butler SF (2010). Geographic informations systems and pharmacoepidemiology: Using spatial cluster detection to monitor local patterns of prescription opioid abuse. Pharmacoepidemiology Drug Safety, 19(6): 627-637.

Bruneau J, Daniel M, Kestens Y, Zang G, and Généreux M (2008). Associations between HIV-related injection behaviour and distance to and patterns of utilisation of syringe-supply programmes. Journal of Epidemiology and Community Health, 62(9): 804-810.

Buxton JA, Preston EC, Mak S, Harvard S, Barley J (2008). Harm reduction strategies and services communities, more than just needles: An evidence-informed approach to enhancing harm reduction supply distribution in British Columbia. Harm Reduction Journal, 5: 37. https://doi.org/10.1186/14777517-5-37 
Chikumba PA (2009). Application of geographic information system (GIS) in drug logistics management information system (LMIS) at district level in Malawi: Opportunities and challenges. In The International Conference on EInfrastructure and E-Services for Developing Countries, Springer Berlin Heidelberg, Berlin Germany, 38: 105-115.

Choi JY, Engel BA, and Farnsworth RL (2005). Web-based GIS and spatial decision support system for watershed management. Journal of Hydroinformatics, 7(3): 165-174.

Colasante E, Molinaro S, and Mariani F (2008). Italian of public health spatial analysis of drug-related hospital admissions: An auto-gaussian model to estimate the hospitalization rates in Italy. Italian Journal of Public Health, 5(4): 253-260.

Cooper HLF, Bossak B, Tempalski B, Des Jarlais DC, and Friedman SR (2009). Geographic approaches to quantifying the risk environment: A focus on syringe exchange program site access and drug-related law enforcement activities. International Journal Drug Policy, 20(3): 217-226.

Curtis AB, Kothari C, Paul R, and Connors E (2013). Using GIS and secondary data to target diabetes-related public health efforts. Public Health Reports, 128(3): 212-220.

Daash A, Srivastava A, Nagpal BN, and Saxena R, Gupta SK (2009). Geographical information system (GIS) in decision support to control malaria - A case study of Koraput district in Orissa, India. Journal of vector borne diseases, 46(1): 72-74.

Davidson PJ, Scholar S, and Howe M (2011). A GIS-based methodology for improving needle exchange service delivery. International Journal of Drug Policy, 22(2): 140-144.

Doi S, Ide H, Ogawa S, Takabayashi K, and Fujita S, Koike S (2015). Probabilistic model to analyze patient accessibility to medical facilities using geographic information systems. Procedia Computer Science, 60: 1631-1639.

Elebead FM, Hamid A, Hilmi HSM, and Galal H (2012). Mapping cancer disease using Geographical Information System (GIS) in Gezira State-Sudan. Journal of Community Health, 37(4): 830-839.

Elmahdi A and Afify A (2007). Development of a GIS tool for qualitative assessment of the Egyptian's quality of life. The Environmentalist, 27(1): 183-194.

Fisher RP and Myers BA (2011). Free and simple GIS as appropriate for health mapping in a low resource setting: a case study in eastern Indonesia. International Journal of Health Geographic, 10(1): 10-15.

Geanuracos CG, Cunningham SD, Weiss G, Forte D, Reid LMH, and Ellen JM (2007). Use of geographic information systems for planning HIV prevention interventions for high-risk youths. American Journal of Public Health, 97(11): 1974-1981.

Green TC and Pope C (2008). Using a GIS framework to assess hurricane recovery needs of substance abuse center clients in Katrina- and Rita-Affected areas. In: Thomas YF, Richardson D, and Cheung I (Eds.), Geography and Drug Addiction: 369-393. Springer, Amsterdam, Netherlands.

Guagliardo MF (2004). Spatial accessibility of primary care: Concepts, methods and challenges. International Journal of Health Geographics, 3: 3. https://doi.org/10.1186/1476072X-3-3

Guerrero EG, Kao D, and Perron BE (2013). Travel distance to outpatient substance use disorder treatment facilities for Spanish-speaking clients. International Journal Drug Policy, 24(1): 38-45.

Guerrero EG, Pan KB, Curtis A, and Lizano EL (2011). Availability of substance abuse treatment services in Spanish: A GIS analysis of Latino communities in Los Angeles County, California. Substance Abuse Treatment, Prevention, and Policy, 6: 21. https://doi.org/10.1186/1747-597X-6-21

Higgs G (2009). The role of GIS for health utilization studies: Literature review. Health Services and Outcomes Research Methodology, 9(2): 84-99.
Hormon JE and Anderson SJ (2003). The design and implementation of geographic information system. John Wiley \& Son, New Jersey, USA.

Hunt ED, Sumner M, Scholten TJ, and Frabutt JM (2008). Using GIS to identify drug markets and reduce drug-related violence a data-driven strategy to implement a focused deterrence model and understand the elements of drug markets. In: Thomas YF, Richardson D, and Cheung I (Eds.), Geography and Drug Addiction: 395-413. Springer, Amsterdam, Netherlands.

Kao D, Torres LR, Guerrero EG, Mauldin R, and Bordnick PS (2014). Spatial accessibility of drug treatment facilities and the effects on locus of control, drug use, and service use among heroin-injecting Mexican American men. International Journal Drug Policy, 25(3): 598-607.

Keenan PB (2003). Spatial decision support system. In: Mora G, Forgionne, and Gupta JND (Eds.), Decision making support systems: Achievement and challenges for the new decade: 28 39. IGI Global: International Publisher of Progressive Academic Research, Philadelphia, USA.

Kenu E, Ganu V, Calys-Tagoe BNL, Yiran GAB, Lartey M, and Richard A (2014). Application of geographical information system (GIS) technology in the control of Buruli ulcer in Ghana. BMC Public Health, 14: 724. https://doi.org/10.1186/1471-2458-14-724

Latkin C, Glass GE, and Duncan T (1998). Using geographic information systems to assess spatial patterns of drug use, selection bias and attrition among a sample of injection drug users. Drug and Alcohol Dependence, 50(2): 167-175.

Lazakidou A (2010). Web-based applications in healthcare and biomedicine. Springer Science and Business Media, Berlin, Germany.

Luo W (2004). Using a GIS-based floating catchment method to assess areas with shortage of physicians. Health and Place, 10(1): 1-11.

Mason M, Cheung I, and Walker L (2004). Substance use, social networks, and the geography of urban adolescents. Substance Use and Misuse, 39(10-12): 1751-1777.

Masoodi M and Rahimzadeh M (2015). Measuring access to urban health services using geographical information system (GIS): A case study of health service management in Bandar Abbas, Iran. International Journal of Health Policy Management, 4(7): 439-445.

McLafferty S (2008). Placing substance abuse: Geographical perspectives on substance use and addiction. In: Thomas YF, Richardson D, and Cheung I (Eds.), Geography and Drug Addiction: 1-16. Springer, Amsterdam, Netherlands.

McLafferty SL (2003). GIS and health care. Annual Review of Public Health, 24(1): 25-42.

Mendoza NS, Conrow L, Baldwin A, and Booth J (2013). Using GIS to describe risk and neighbourhood-level factors associated with Substance Abuse Treatment Outcomes. Journal of Community Psychology, 41(7): 799-810.

Mennecke BE (1997). Understanding the role of geographic information technologies in business: Applications and research directions. Journal of Geographic Information and Decision Analysis, 1(1):44-68.

Mishra S (2009). GIS in Indian retail industry: A strategic tool. International Journal of Marketing Studies, 1(1): 50-57.

Mullner RM, Chung K, Croke KG, and Mensah EK (2004). Geographic information systems in public health and medicine. Journal of Medical System, 28(3): 215-222.

O'Neill L (2003). Estimating out-of-hospital mortality due to myocardial infarction. Health Care Management Science, 6(3): 147-154.

Pang TTP and Lee SS (2008). Measuring the geographic coverage of methadone maintenance programme in Hong Kong by using geographic information system (GIS). International 
Journal of Health Geographics, 7: 5. https://doi.org/ 10.1186/1476-072X-7-5

Petronis KR, Johnson CC, and Wish ED (1995). Location of drugusing arrested and treatment centres in Washington D.C.: A geocoding demonstration Project. National Institute of Justice, Washington, USA. Available online at: https://www.ncjrs.gov/pdffiles1/Digitization/155173NCJRS. pdf.

Rafalski E and Mullner R (2003). Ensuring HIPAA compliance using data warehouse for healthcare marketing. Journal of Consumer Marketing, 20(7): 629-633.

Rayed CA (2012). Using GIS for modelling a spatial DSS for industrial pollution in Egypt. American Journal of Geographic Information System, 1(4): 100-104.

Reddy RL, Apoorva B, Snigdha S, and Spandana K (2013). GIS applications in land use and land development of a city. International Journal of Emerging Technology and Advanced Engineering, 3(5): 303-308.

Rosero-Bixby L (2004). Spatial access to health care in Costa Rica and its equity: A GIS-based study. Social Science and Medicine, 58(7): 1271-1284.

Sanders LJ, Aguilar GD, and Bacon CJ (2013). A spatial analysis of the geographic distribution of musculoskeletal and general practice healthcare clinics in Auckland, New Zealand. Applied Geography, 44: 69-78.

Seid A, Gadisa E, Tsegaw T, Abera A, Teshome A, Mulugeta A, Herrero M, Argaw D, Jorge A, Kebede A, and Aseffa A (2014). Risk map for cutaneous leishmaniasis in Ethiopia based on environmental factors as revealed by geographical information systems and statistics. Geospatial Health, 8(2): 377-387.

Shirayama Y, Phompida S, and Shibuya K (2009). Geographic information system (GIS) maps and malaria control monitoring: intervention coverage and health outcome in distal villages of Khammouane province, Laos. Malaria journal, 8: 217. https://doi.org/10.1186/1475-2875-8-217

Sorensen SL (1997). Smart mapping for law enforcement settings: Integrating GIS and GPS for dynamic, near-real time applications and analyses. In: David W and Tom ME (Eds.), Crime mapping and crime prevention: 349-378. Criminal Justice Press, New York, USA.
Srivastava A, Nagpal BN, Joshi PL, Paliwal JC, and Dash AP (2009). Identification of malaria hot spots for focused intervention in tribal state of India: A GIS based approach. International Journal of Health Geographics, 8: 30. https://doi.org/ 10.1186/1476-072X-8-30

Thomas Y, Richardson D, and Cheung I (2008). Integrating geography and social epidemiology in drug abuse research. In: Thomas YF, Richardson D, and Cheung I (Eds.), Geography and Drug Addiction: 17-26. Springer, Amsterdam, Netherlands.

Toriman ME, Abdullah SNF, Azizan IA, Kamarudin MKA, Umar R, and Mohamad N (2015). Spatial and temporal assessment on drug addiction using multivariate analysis and GIS. Malaysian Journal of Analytical Sciences, 19(6): 1361-1373.

Wen TH, Lin NH, Chao DY, Hwang KP, Kan CC, Lin, Wu JTS, Huang SYJ, Fan IC, and King CC (2010). Spatial-temporal patterns of dengue in areas at risk of dengue hemorrhagic fever in Kaohsiung, Taiwan, 2002. International Journal of Infectious Diseases, 14(4): 334-343.

Williams CT and Latkin CA (2007). Neighborhood socioeconomic status: Personal network attributes, and use of heroin and cocaine. American Journal of Preventive Medicine, 32(6): 203210.

Wong NS, Lee SS, and Lin $H$ (2010). Assessing the spatial distribution of methadone clinic clients and their access to treatment. Harm Reduction Journal, 7: 14. https://doi.org/10.1186/1477-7517-7-14

Yomralioglu T, Colak EH, and Aydinoglu AC (2009). Georelationship between cancer cases and the environment by GIS: A case study of Trabzon in Turkey. International Journal of Environmental Research and Public Health, 6(12): 31903204.

Zhou YB, Liang S, Wang QX, Gong YH, Nie SJ, Nan L, Yang AH, Lioa Q, Song XX, and Jiang QW (2014). The geographic distribution patterns of HIV-, HCV- and co-infections among drug users in a national methadone maintenance treatment program in Southwest China. BMC Infectious Diseases, 14: 134. https://doi.org/10.1186/1471-2334-14-134

Zhu L, Gorman DM, and Horel S (2006). Hierarchical bayesian spatial models for alcohol availability, drug "hot spots" and violent crime. International Journal of Health Geographics, 5: 54. https:///doi.org/10.1186/1476-072X-5-54 